\title{
Body water content of extremely preterm infants at birth
}

Gary Hartnoll, Pierre Bétrémieux, Neena Modi

\begin{abstract}
Background-Preterm birth is often associated with impaired growth. Small for gestational age status confers additional risk.

Aim-To determine the body water content of appropriately grown (AGA) and small for gestational age (SGA) preterm infants in order to provide a baseline for longitudinal studies of growth after preterm birth.

Methods-All infants born at the Hammersmith and Queen Charlotte's Hospitals between 25 and 30 weeks gestational age were eligible for entry into the study. Informed parental consent was obtained as soon after delivery as possible, after which the extracellular fluid content was determined by bromide dilution and total body water by $\mathrm{H}_{2}{ }^{18} \mathrm{O}$ dilution.

Results-Forty two preterm infants were studied. SGA infants had a significantly higher body water content than AGA infants (906 (833-954) and 844 (637-958) $\mathrm{ml} / \mathrm{kg}$ respectively; median (range); $p=0.019)$. There were no differences in extracellular and intracellular fluid volumes, nor in the ratio of extracellular to intracellular fluid. Estimates of relative adiposity suggest a body fat content of about $7 \%$ in AGA infants, assuming negligible fat content in SGA infants and lean body tissue hydration to be equivalent in the two groups.

Conclusions-Novel values for the body water composition of the SGA preterm infant at 25-30 weeks gestation are presented. The data do not support the view that SGA infants have extracellular dehydration, nor is their regulation of body water impaired.

(Arch Dis Child Fetal Neonatal Ed 2000;83:F56-F59)
\end{abstract}

Keywords: body composition; water compartments; growth restriction; newborn; preterm; dehydration

Pédiatrique, Rennes,

France

P Bétrémieux

Division of Paediatrics and Neonatal

Medicine, Imperial

College School of

Medicine,

Hammersmith

Hospital, Du Cane

Road, London

W12 0NN, UK

N Modi

Correspondence to:

Dr Modi

email: nmodi@ic.ac.uk

Accepted 21 February 2000 than 30 weeks gestation and to compare the body composition of AGA and SGA infants.

The first report of the composition of the human fetus appeared in 1857 with the work of von Bezold. ${ }^{2}$ This was followed by a number of cadaver studies, ${ }^{3-5}$ up to and including that of Widdowson and Spray in $1950 .^{6}$ It is not known whether the early cadaver studies involved fetuses that were AGA or SGA, and in recent years, with the development of techniques to assess body composition in vivo, few cadaver studies have been carried out. More recent in vivo studies have largely excluded the preterm SGA infant. The only available data on the body composition of such infants is from a study by van der Wagen et $a l^{7}$ in which seven infants with gestations ranging from 32 to 39 weeks were investigated. To our knowledge, there are no published data on the body composition of SGA preterm infants of less than 30 weeks gestation.

\section{Methods}

Measurements of body water compartments at birth were made as part of a larger study investigating fluid balance in preterm infants. Inborn infants between 25 and 30 weeks gestation admitted to the neonatal units at the Hammersmith and Queen Charlotte's Hospitals, London, UK were eligible for recruitment. The study was approved by the institutional research ethics committee, and written informed parental consent was obtained. Infants with major congenital abnormalities and obvious derangements of fluid balance such as hydrops were excluded.

SGA infants were defined as those who were below the 9th centile on the Child Growth Foundation charts (Child Growth Foundation 1996/1, 2 Mayfield Avenue, London W4 1PW, UK). Gestational age was determined from maternal dates confirmed by an early ultrasound dating examination.

Total body water (TBW) and extracellular fluid volume (ECFV) were determined as soon as possible after delivery. TBW was measured using $\mathrm{H}_{2}{ }^{18} \mathrm{O}$ dilution as previously described. ${ }^{8}$ Briefly, after taking a baseline sample of blood, the infant was given $1 \mathrm{ml} / \mathrm{kg}$ water enriched with $\mathrm{H}_{2}{ }^{18} \mathrm{O}$. The exact amount of water administered was determined by weighing the syringe before and after administration of the water on a chemical balance accurate to $\pm 0.0001 \mathrm{~g}$. The water was administered by nasogastric tube, and the tube was flushed with a further $2 \mathrm{ml}$ sterile water for injection. Two further blood samples were taken as close to three and six hours after $\mathrm{H}_{2}{ }^{18} \mathrm{O}$ administration as possible, the exact time being noted (blood sampling 
was timed to coincide with clinical sampling whenever possible). The sample was spun immediately, and the serum separated and frozen at $-20^{\circ} \mathrm{C}$ until analysed. Exact times of sampling were noted in order to extrapolate backwards to a concentration at time zero $\left(\mathrm{C}_{0}\right)$. Extrapolation to time zero was performed by linear regression on the $\log _{\mathrm{e}}$ values of ${ }^{18} \mathrm{O}$ concentrations (ppm). The $\mathrm{H}_{2}^{18} \mathrm{O}$ samples were analysed as previously described, ${ }^{8}$ and TBW calculated using the method of Schoeller et al. ${ }^{9}$ ECFV was determined using bromide dilution. After a baseline blood sample had been obtained, $1 \mathrm{ml} / \mathrm{kg} \mathrm{NaBr}$ solution containing $100 \mathrm{mg} / \mathrm{ml} \mathrm{NaBr}$ was administered intravenously, using vascular access sited for clinical purposes. $\mathrm{NaBr}$ equilibrates rapidly if given intravenously. ${ }^{10}$ In addition, the half life is very long, so that once equilibration is reached only a single sample is needed to calculate ECFV. We obtained two samples after baseline, at the same time as the samples for TBW estimation, to confirm that equilibration had taken place. They were then averaged to provide a single measure. After being spun, $10 \mu \mathrm{l}$ aliquots of serum were pipetted on to $1 \mathrm{~cm}$ diameter filter papers. These were dried in air before being sealed in plastic cuvettes for despatch to the Centre for Analytical Research in the Environment, Imperial College at Silkwood Park, for analysis by neutron activation. Assay results are expressed as $\mu \mathrm{g}$ bromide $/ \mathrm{ml}$ serum and this value is used in the following equation ${ }^{11}$ :

$\mathrm{ECFV}=$ (Amount of $\mathrm{Br}$ administered/serum $[\mathrm{Br}]) \times 0.90 \times 0.95 \times 0.934$

The amount of bromide administered was calculated as follows:

\section{Bromide injected $=$ \\ Weight of $\mathrm{NaBr}$ solution given (g) $\times[\mathrm{NaBr}$ soln $] \times$ conversion factor Specific gravity of $\mathrm{NaBr}$ solution}

The weight of $\mathrm{NaBr}$ solution given was measured by weighing the syringe before and after administration of the solution using a chemical balance accurate to $\pm 0.0001 \mathrm{~g}$. ECFV was calculated as:

$$
\begin{aligned}
& \mathrm{ECFV}(\mathrm{ml})= \\
& \mathrm{NaBr} \text { solution administered }(\mathrm{g}) \\
& \times 10^{5} \times 0.777 \times 0.9 \times 0.95 \times 0.934 \\
& \text { Serum bromide concentration } \times 1.073
\end{aligned}
$$

where 0.90 is the correction factor for intracellular bromide, 0.95 corrects for the Donnan equilibrium across the cell membrane, 0.934 corrects for the proportion of water in serum, ${ }^{12}$ 0.777 is the factor to convert $\mathrm{mg} / \mathrm{ml} \mathrm{NaBr}$ to $\mathrm{mg} / \mathrm{ml}$ bromide, and 1.073 is the specific gravity of $\mathrm{NaBr}$ solution (manufactured by the Department of Pharmacology, Northwick Park

Table 1 Study population consisting of seven small for gestational age (SGA) and 35 appropriately grown (AGA) infants

\begin{tabular}{llll}
\hline & $S G A$ & $A G A$ & $p$ Value \\
\hline Birth weight (g) & $760(420-1020)$ & $990(710-1570)$ & 0.009 \\
Gestation (weeks $\left.{ }^{\text {days }}\right)$ & $28^{1}\left(26^{5}-29^{\circ}\right)$ & $27^{0}\left(25^{5}-30^{\circ}\right)$ & 0.24 \\
Male:female & $5: 2$ & $19: 16$ & 0.68
\end{tabular}

Values are median (range).
Hospital, Harrow, Middlesex, UK). The Donnan equilibrium correction is necessary because intravascular anionic proteins cause differential movement of bromide ions across the capillary membrane such that the concentration of bromide in the interstitial fluid is about $5 \%$ greater than in serum water. ${ }^{13}{ }^{14}$

Intracellular fluid volume (ICFV) was calculated by subtracting ECFV from TBW, and body solid content by subtracting TBW from body weight. We estimated the fraction of lean body mass in AGA babies as TBW for AGA babies/TBW for SGA babies based on the assumption of a $0 \%$ adipose tissue content in SGA babies. Fat content was then calculated as 1 - lean mass. We also determined whether, at this calculated fat content, there was any significant difference in lean body mass water content between the groups, as might be expected if lean body tissue hydration is the same in both groups and adipose tissue is anhydrous.

Statistical analysis was carried out using Intercooled Stata version 4.0. ${ }^{15}$ Unless otherwise stated, results are quoted as median and range. Comparisons were made using the Mann-Whitney two sample statistic for continuous variables and Fisher's exact test for categorical variables.

\section{Results}

Forty two preterm infants were studied. Measurements were made within 18 hours of birth. Seven infants were SGA and 35 were AGA. Birth weights were $760(420-1020)$ and 990 (710-1570) g and gestational ages 28 (26-29) and $27(25-30)$ weeks for SGA and AGA infants respectively. There were no differences between the groups with respect to sex or gestational age (table 1).

Body composition differed between the groups (table 2). SGA infants had a significantly higher body water content, when expressed per unit body weight, than AGA infants (906 (833-954) and 844 (637-958) $\mathrm{ml} / \mathrm{kg}$ respectively; $\mathrm{p}=0.019)$ and therefore a correspondingly lower body solid content ( 94 (46-167) and 157 (42-363) g/kg respectively.

There was no significant difference in ECFV (SGA, 511 (461-581) ml/kg; AGA, 505 (311$569) \mathrm{ml} / \mathrm{kg} ; \mathrm{p}=0.52$ ) or the ratio of ECFV to ICFV (SGA, 1.3 (1.0-1.8); AGA, 1.4 (0.72.4); $\mathrm{p}=0.7)$

Assuming 0\% fat content in SGA babies, we calculated the fraction of lean body mass in AGA babies as 844/906 (TBW for AGA babies/TBW for SGA babies) $=0.93$. This suggests a fat content in AGA infants of $7 \%$. Reanalysis of our data assuming $0 \%$ fat content

Table 2 Body composition analyses

\begin{tabular}{llll}
\hline & SGA & AGA & p Value* \\
\hline TBW (ml/kg) & $906(833-954)$ & $844(637-958)$ & 0.019 \\
ECFV (ml $/ \mathrm{kg})$ & $511(461-581)$ & $505(311-569)$ & 0.52 \\
ICVF (ml/kg) & $386(314-463)$ & $355(241-524)$ & 0.33 \\
\hline
\end{tabular}

Values are median (range).

${ }^{\star}$ Mann-Whitney two sample statistic.

SGA, small for gestational age; AGA, appropriately grown for SGA, small for gestational age; AGA, appropriately grown fo
gestational age; TBW, total body water; ECFV, extracellular fluid volume; ICVF, intracellular fluid volume. 
Table 3 Values for total body water (TBW) content of lean body mass assuming different body fat content as a percentage of body weight in the appropriately grown $(A G A)$ infants

\begin{tabular}{lll}
\hline & $\begin{array}{l}\text { TBW (ml/kg lean } \\
\text { weight })\end{array}$ & $\begin{array}{l}p(S G A v \\
A G A)\end{array}$ \\
\hline SGA (0\% fat) & $906(833-954)$ & - \\
AGA (0\% fat) & $844(637-958)$ & 0.019 \\
AGA (2\% fat) & $861(650-978)$ & 0.058 \\
AGA (4\% fat) & $879(664-998)$ & NS \\
AGA (7\% fat) & $908(685-1030)$ & NS \\
\hline
\end{tabular}

Values are median (range).

SGA, small for gestational age.

in SGA babies and a range of possible body fat content in AGA infants confirmed that, at an assumed $7 \%$ body fat content in AGA babies, there was no longer a significant difference in TBW per unit lean body mass between the groups (table 3 ).

\section{Discussion}

We have presented novel data on the body composition of the preterm infant and provided a baseline for longitudinal studies of growth after preterm birth. We are unaware of any previous studies reporting in vivo measurements of body water content of SGA babies below 30 weeks gestation. We have shown that the body composition of preterm SGA infants differs significantly from that of AGA babies of equivalent gestational age, with differences in TBW and both an absolute and a relative reduction in body solid mass.

Our measurements of body composition for AGA infants are comparable with the limited published data. Bauer et $a l^{16}$ studied a group of infants of comparable gestational age to those in our study, although SGA babies were specifically excluded. TBW content was within our range of values. The data of Heimler et al, ${ }^{17}$ derived from infants of slightly longer gestation ( $30.7 \pm 2.4$ weeks), are also within the range of results of the present study. All of the published cadaver studies $^{2-4}$ report values that fall within the range defined by the three in vivo studies reported here. Table 4 lists studies in which body composition was determined within the first 24 hours after birth and in which it was possible to extract values for infants below 32 weeks gestation. Results from the three cadaver studies are included for comparison.

Deuterium oxide dilution has also been used to determine TBW. However, deuterium is harmful at levels greater than $10 \% .{ }^{18}$ In

Table 4 Previously published body water compartments ( $\mathrm{ml} / \mathrm{kg}$ ) for all gestations 22 to 32 weeks, with values from present study for comparison

\begin{tabular}{|c|c|c|c|c|c|c|c|}
\hline \multirow[b]{2}{*}{ Reference } & \multirow[b]{2}{*}{ Date } & \multicolumn{3}{|l|}{$T B W$} & \multicolumn{3}{|l|}{$E C F V$} \\
\hline & & $S G A$ & $A G A$ & $N / S$ & $S G A$ & $A G A$ & $N / S$ \\
\hline${ }^{\star}$ von Bezold ${ }^{2}$ & 1857 & & & 808 (1) & & & \\
\hline${ }^{\star}$ Fehling $^{3}$ & 1877 & & & $846(8)$ & & & \\
\hline${ }^{\star}$ Givens et $a l^{4}$ & 1933 & & & $823(6)$ & & & \\
\hline Shaffer et $a l^{20}$ & 1989 & & & & & $410(20)$ & \\
\hline Bauer et al ${ }^{21}$ & 1989 & & & & & $452(13)$ & \\
\hline Bauer et al ${ }^{16}$ & 1991 & & $792(8)$ & & & $444(8)$ & \\
\hline Heimler et $a l^{17}$ & 1993 & & $866(14)$ & & & $504(14)$ & \\
\hline Present study & 2000 & $906(7)$ & $844(35)$ & & $511(7)$ & $505(35)$ & \\
\hline
\end{tabular}

Numbers in parentheses are the sample size.

${ }^{\star}$ Cadaver studies.

SGA, small for gestational age; AGA, appropriately grown for gestational age; TBW, total body water; ECFV, extracellular fluid volume; N/S, not stated. addition, the hydrogen in this isotope exchanges with the labile hydrogen of both protein and other body constituents, ${ }^{19}$ leading to an overestimate of TBW by $1-5 \%$. We elected to use $\mathrm{H}_{2}{ }^{18} \mathrm{O}$ enrichment because $\mathrm{H}_{2}{ }^{18} \mathrm{O}$ is a stable, non-radioactive, non-toxic, naturally occurring isotope normally present in the body. We have previously determined dilution kinetics for this marker in preterm infants. ${ }^{8}$

Shaffer et $a l^{20}$ and Heimler et $a l^{17}$ used the bromide dilution technique to determine ECFV, and Bauer et $a l^{1621}$ used sucrose dilution. Sucrose is commonly used as a marker for ECFV estimation, as it is not metabolised and is thought to remain in the extracellular space. However, it is slow to enter connective tissue water ${ }^{22}$ and it does not enter the cerebrospinal fluid or the gastrointestinal fluids, and this method will therefore tend to underestimate ECFV. ${ }^{23}$ An additional problem when studying extremely small infants is that a much larger total blood sample volume is needed. ${ }^{24}$ In contrast, bromide ions penetrate to all parts of the extracellular fluid space rapidly and evenly, although $10-13 \%$ of administered bromide is intracellular. ${ }^{25}{ }^{26}$ It is therefore conventional to correct the calculated bromide space by a factor of $10 \%$, but for this reason measurements of ECFV using bromide dilution may be overestimates. This may explain why the ECFV values for the AGA babies in this study and that of Heimler et al, ${ }^{17}$ although in close agreement with each other, are higher than those of Bauer et al. ${ }^{16}{ }^{21}$ Although ECFV determinations for infants from 25-31 weeks gestation carried out by Shaffer et $a l^{20}$ using bromide dilution are lowest of all, this appears to be a reflection of the fact that the sample was obtained 90 minutes after the dose was administered. At this point, the bromide may well not have fully equilibrated, resulting in relatively less than $10 \%$ in the intracellular compartment and relatively more in the extracellular space, and hence an underestimate of ECFV.

Studies of term infants have also shown SGA infants to have a greater TBW content, ${ }^{27} 28$ and this is attributed to their lower body fat content, ${ }^{29}$ as adipose tissue in mature subjects is anhydrous. If this is also the case in extremely immature infants, for whom little is known about the composition of adipose tissue, an estimate of adiposity may be derived by determining the percentage difference in assumed fat content at which water content per unit of lean body mass is similar in AGA and SGA infants. If one assumes $0 \%$ fat content in these extremely preterm SGA infants, then reanalysis of our data suggests a fat content of about $7 \%$ in AGA infants. This would account for the differences in the TBW measurements between the AGA and SGA babies. Petersen et $a l^{30}$ using dual photon absorptiometry with ${ }^{153} \mathrm{Ga}$, detected no fat in either AGA or SGA preterm infants, between 31 and 36 weeks gestation and at term, $2 \%$ in SGA infants, and $13 \%$ in AGA infants. However, the cadaver studies of Fehling ${ }^{3}$ suggest a mean fat content of $2.1 \%$ in infants of 24-32 weeks gestation. This is similar to data from Iob and Swanson ${ }^{5}$ for gestations of between 24 and 32 weeks. 
Widdowson and Spray ${ }^{6}$ present their data by body weight and suggest about $2.5 \%$ body fat at $1000 \mathrm{~g}$. Enzi et $a \mathrm{l}^{1}$ showed a 3\% difference in body fat mass, measured by anthropometric means, between AGA and SGA infants at 35 weeks gestation. Summary data from Ziegler et $a l^{32}$ show a body fat content of $0.7-4.9 \%$ for the gestational age range 25-30 weeks. Our estimated difference therefore appears reasonable.

It is notable that the ratio of extracellular to intracellular water was not significantly different. This suggests that SGA infants are not dehydrated, as has been suggested. ${ }^{33}{ }^{34}$ Further, as it is unlikely that SGA infants would have a greater cell volume, they must either have a reduced cell volume with relative increase in cell number, with the implication that catch up growth is possible, or preservation of cell volume albeit with a reduction in cell number, in which case catch up growth is unlikely. It does, however, appear that the regulation of body water distribution is unimpaired in SGA infants.

P B was supported by a European Union Human Capital and Mobility Grant and SESEP. We also gratefully acknowledge the assistance of Ms Caroline Doré, Medical Statistics Unit, Hammersmith Hospital and Dr Susan Parry and Dr Roger Benzing at the Centre for Analytical Research in the Environment, at the Centre for Analytical Research in the

Imperial College at Silkwood Park, Slough, UK. Data were collected by G H and P B and analysed by G H. The paper was written by $\mathrm{G} \mathrm{H}$ and $\mathrm{N} M$.

1 Barker DJP, Gluckman PD, Godfrey KM, Harding JE, Owens JA, Robinson JS. Fetal malnutrition and cardiovasOwens JA, Robinson JS. Fetal malnutrition and cardio

2 von Bezold A. Untersuchungen uber die Vertheilung von Wasser, organischer Materie und anorganischen VerbindWasser, organischer Materie und anorganischen Verbind-
ungen in Thierreiche. Zeitschrifte für wissenschafte Zoologie ungen in Thierre

3 Fehling H. Beiträge zur Physiologie das placentaren stoffverkhers. Archiv Gynäkologie 1877;2523.

4 Givens MH, Macey IG. The chemical composition of the human fetus. F Biol Chem 1933;102:7-17.

5 Iob V, Swanson WW. Mineral growth of the human fetus. American fournal of Diseases in Children 1934;47:302-6.

6 Widdowson EM, Spray CM. Chemical development in utero. Arch Dis Child 195126:205-14.

7 van der Wagen A, Okken A, Zweens J, Zijlstra WG. Composition of postnatal weight loss and subsequent weight gain in small for dates newborn infants. Acta Paediatr Scand 1985; 74:57-61.

8 Tang W, Modi N, Clark P. Dilution kinetics of $\mathrm{H}_{2}{ }^{18} \mathrm{O}$ for the measurement of total body water in preterm babies in the measurement of total body water in preterm babies in

9 Schoeller DA, van Santen E, Peterson DW, Dietz W, Jaspan J, Klein PD. Total body water measurement in humans with ${ }^{18} \mathrm{O}$ and ${ }^{2} \mathrm{H}$ labelled water. Am f Clin Nutr with ${ }^{18} \mathrm{O}$ and ${ }^{2} \mathrm{H}$

10 Tang W. The validation of bioelectrical impedance analysis to measure body water distribution in preterm neonates University of Sheffield: MD thesis, 1996.
11 Bell EF, Ziegler EE, Forbes GB. Corrected bromide space [letter]. Pediatr Res 1984;18:392-3.

12 Cassady G. Bromide space studies in infants of low birth weight. Pediatr Res 1970;4:14-24.

13 Gamble JL, Robertson JS. Volume of distribution of radioactive chloride in dogs: comparison with sodium bromide and inulin. Am f Physiol 1952;171:659.

14 Cheek DB, Talbert JL. Extracellular volume (and sodium) and body water in infants. In: Cheek DB, ed. Human growth: body composition, cell growth, energy and intelligence. Philadelphia: Lippincott 1968:117-34.

15 Intercooled Stata. 1995; version 4.0 Stata Corporation, 702 University Drive East, College Station. Texas, USA.

16 Bauer K, Bovermann G, Roithmaier A, Gotz M, Proiss A, Versmold HT. Body composition, nutrition, and fluid balance during the first two weeks of life in preterm neonates weighing less than 1500 grams. F Pediatr 1991;118:61520

17 Heimler R, Doumas BT, Jendrzejczak BM, Nemeth PB, Hoffman RG, Nelin LD. Relationship between nutrition, weight change, and fluid compartments in preterm infants during the first week of life. $\mathcal{F}$ Pediatr $1993 ; 122: 110-14$.

18 Thomson JF. Biological effects of deuterium. New York: Pergamon Press, 1963:85.

19 Culebras JM, Moore FD. Total body water and the exchangeable hydrogen. I. Theoretical calculation of nonaqueous exchangeable hydrogen in man. Am $f$ Physiol 1977;232:R54-9.

20 Shaffer SG, Meade VM. Sodium balance and extracellular volume regulation in very low birth weight infants. 7 Pediatr 1989;115:285-90.

21 Bauer K, Versmold H. Postnatal weight loss in preterm neonates less than $1,500 \mathrm{~g}$ is due to isotonic dehydration of the extracellular volume. Acta Paediatr Scand 1989;360:37-42.

22 Nichols G, Weil WB, Wallace WM. The direct measurement of the extracellular phase of tissues. $\mathcal{F}$ Clin Invest 1953;31:652.

23 Gamble JL, Robertson JS. Chloride, bromide, sodium and sucrose spaces in man. $\mathcal{F}$ Clin Invest 1953;32:483.

24 Bauer K, Versmold H, Prolss A, De Graaf SS, Meeuwsen Van der Roest WP, Zijlstra WG. Estimation of extracellular volume in preterm infants less than $1500 \mathrm{~g}$, children, and adults by sucrose dilution. Pediatr Res 1990;27:256-9.

25 Edelman IS, Leibman J. Anatomy of the body fluids. $A m \mathcal{F}$ Med 1959;27:256.

26 Cheek DB. Extracallular volume: its structure and measurement and the influence of age and disease. $f$ Pediatr 1961;58:103-22.

27 Cassady G, Milstead RR. Antipyrine space studies and cell water estimates in infants of low birth weight. Pediatr Res 1971;5:673-82.

28 Cheek DB, Wishart J, MacLennan AH, Haslam R. Cell hydration in the normally grown, the premature and the low weight for gestational age infant. Early Hum Dev 1984;10:75-84

29 Bauer K, Cowett RM, Howard GM, van Epp J, Oh W. Effect of intrauterine growth retardation on postnatal weight change in preterm infants. F Pediatr 1993;123:301-6.

30 Petersen S, Gotfredsen A, Knudsen FU. Lean body mass in small for gestational age and appropriate for gestational age infants. F Pediatr 1988;113:886-9.

31 Enzi G, Zanardo V, Caretta F, Inelmen EM, Rubaltelli F. Intrauterine growth and adipose tissue development. $A m \dot{F}$ Clin Nutr 1981;34:1785-90.

32 Ziegler EE, O'Donnell AM, Nelson SE, Fomon SJ. Body composition of the reference fetus. Growth 1976;40:32941.

33 Scott KE, Usher R. Fetal malnutrition: its incidence, causes, and effects. Am f Obstet Gynecol 1966;94:951-63.

34 Sinclair JC, Scopes JW, Silverman WA. Metabolic reference standards for the neonate. Pediatrics 1967;39:724-32. 